\title{
As políticas públicas de avaliação do livro didático: múltiplas experiências
}

\author{
Public policy evaluation of the textbook: multiple experiences
}

Tatyana de Amaral Maia*

\section{Oliveira, Margarida Maria Dias; Costa, Aryana (Org.) \\ Para que(m) se avalia? Livros Didáticos e Avaliações (Brasil, Chile, Espa- nha, Japão, México e Portugal) \\ Natal: Ed. UFRN, 2014. 164p.}

O livro didático é um instrumento importante na "transposição didática" dos saberes de referência, tornando-se um dos principais recursos utilizados por professores e alunos nas salas de aula. Inúmeros pesquisadores têm se debruçado sobre esse objeto cultural, reconhecendo a sua centralidade no processo de ensino-aprendizagem. Nas últimas décadas, com a renovação do Ensino de História ampliaram-se as perspectivas da análise do livro didático. As pesquisas mais recentes, ainda que se dediquem à análise dos conteúdos, buscam investigar os múltiplos agentes que interferem no processo de produção dos livros didáticos; as políticas públicas; a relação entre historiografia e a historiografia didática; a conexão entre textos e imagens; o papel das atividades; os usos e apropriações que alunos e professores fazem dos livros no seu cotidiano (Rocha, 2009; Caimi, 2009; Miranda; Luca, 2004).

O livro Para que(m) se avalia? Livros Didáticos e Avaliações (Brasil, Chile, Espanha, Japão, México e Portugal) organizado por Margarida Maria Dias de Oliveira e Aryana Costa, insere-se nesse lugar de renovação das pesquisas sobre o livro didático. A obra composta por seis capítulos é dedicada às políticas de avaliação dos livros didáticos em diferentes países. Um dos méritos do livro é a possibilidade de conhecermos outros processos de avaliação e, por comparação, observar as semelhanças e diferenças entre as políticas públicas

\footnotetext{
* Doutora em História. Professora adjunta do Departamento de História e do Programa de Pós-Graduação em História da Pontifícia Universidade Católica do Rio Grande do Sul (PUCRS). tatyana.maia@pucrs.br
} 
brasileiras e as dos demais países, favorecendo a visualização da qualidade e complexidade do nosso modelo avaliativo.

Os autores da coletânea reconhecem que o livro didático seleciona, organiza e sistematiza os conteúdos, forjando uma historiografia didática distinta da produção do conhecimento científico produzido nas instituições universitárias e acadêmicas. A multiplicidade de atores envolvidos na produção dessa historiografia didática, incluindo as demandas de professores e alunos, são aspectos a serem considerados no processo de análise dos livros. Assim, não se trata mais de compreender o livro didático como uma produção simplificada do conhecimento histórico, mas como uma produção que resulta de um diálogo não-linear com Estado, professores, comunidade científica, interesses editoriais, pais e alunos.

Os autores também destacam a manutenção nas avaliações do lugar da "História pátria" no Ensino de História nos diferentes países, ainda que requalificado, com a inclusão de novos atores, grupos sociais, múltiplas escalas espaciais e temporalidades. Cabe aqui uma ressalva: em tempos de globalização e fortes fluxos migratórios, é preciso estar atento para que o ensino da "História pátria" comporte a relação supranacional que caracteriza a modernidade e, sobretudo, os dias atuais.

As diferentes experiências avaliativas entre os países podem ser compreendidas a partir de dois eixos centrais, gerando semelhanças e diferenças nas avaliações realizadas em cada país: primeiro, a relação do Estado com o livro didático, principalmente quando há programas de compra e distribuição gratuita de livros didáticos; segundo, a existência ou não de um currículo comum. Brasil, México, Japão e Chile possuem uma política de distribuição gratuita desses livros.

No Brasil, a política de livros didáticos possui números impactantes. Como demonstram Itamar Freitas e Margarida Dias de Oliveira, 31 milhões de alunos, de 116.824 escolas, devem receber anualmente as coleções de livros didáticos das diversas disciplinas escolares e que cobrem todas as séries do Ensino Fundamental e Médio. As inúmeras etapas de avaliação incluem o lançamento de edital público, a presença de professores universitários e da educação básica como avaliadores, o critério do duplo cego. Os resultados das avaliações estão disponíveis a consulta e também constituem um valioso acervo para os pesquisadores, apresentando indicadores importantes para a análise 
dos livros didáticos brasileiros. Freitas e Oliveira destacam que os resultados do processo avaliativo indicam a existência de certa padronização nos livros didáticos; a preocupação das editoras em restringir seus investimentos aos critérios mínimos do edital; o acúmulo dos conteúdos, na busca ficcional por um ensino que incorpore todos os objetos da História-Ciência; a opção pela constante revisão dos livros ao invés de publicações efetivamente renovadas; a timidez no uso de inovações didáticas (Freitas; Oliveira, 2015, p.17).

Em análise comparativa, os autores Laura Lima Muñiz, Marcela Arece Tena e María Del Refugio Plazola Díaz produzem uma reflexão sobre os processos de avaliação e usos dos livros didáticos no Chile, Espanha e Japão. No Chile, os livros são distribuídos gratuitamente e avaliados a partir de critérios de qualidade pedagógica e científica e de viabilidade econômica. Cabe aos professores nas escolas a escolha dos livros previamente indicados pelo Ministério da Educação. Ao contrário de outros países, na Espanha não há processo de avaliação centralizada pelo Estado. Os professores têm plena autonomia na escolha dos livros, cabendo a eles a avaliação sobre a qualidade dos livros. A associação das editoras tem por iniciativa própria promovido ações para melhoria dos livros didáticos (Muñiz; Tena; Díaz, 2015, p.39). No Japão, o Estado atua no processo de controle da produção e avaliação dos livros didáticos, interferindo diretamente no conteúdo. A distribuição é gratuita a todos os alunos, incluindo aqueles que estudam nas escolas privadas. (ibidem, p.43).

O capítulo de Rafael Valls é dedicado às contribuições trazidas pelas pesquisas recentes sobre a análise e avaliação dos livros didáticos no contexto espanhol. As novas pesquisas estão marcadas pelo processo de renovação da Didática da História, da História Cultural, da Teoria da História e da Educação Histórica. O autor oferece uma sistematização das teorias elaboradas por Weinbrenner, Selander e Rüsen, entendendo-as como uma contribuição ao tratamento do livro didático na formação inicial (Valls, 2015, p.55).

O quarto capítulo, de Laura H. Lima Muñiz, traz uma reflexão sobre a avaliação dos livros didáticos no México. Trata-se de um processo avaliativo complexo em consonância com aspectos caros ao ensino de História atual: a multiperspectiva; a relação local-global; a pluralidade dos tempos; a relação passado-presente-futuro; a contribuição das diversas etnias na formação da história nacional; a interdisciplinaridade; o significado da História para a vida cotidiana (Muñiz, 2015, p.74). Ao lado de uma análise sobre o processo 
avaliativo, a autora também se dedica aos usos e apropriações realizadas pelos professores em sala de aula. Aliás, ainda são poucas as pesquisas que têm se ocupado dos usos dos livros didáticos por professores e alunos, a despeito da crescente importância da aprendizagem histórica como objeto de pesquisa no ensino de História. Recorrendo a questionários realizados com docentes a autora indagou sobre os seguintes aspectos: o incentivo à leitura, ao ditado, à cópia e à análise de imagens; e o uso de materiais complementares aos livros didáticos, como consulta a outros livros, filmes e informações na internet.

No quinto capítulo, Luísa Díaz González debruça-se sobre os livros adquiridos para as bibliotecas escolares e presentes nas bibliotecas de salas de aula no México. A autora contribui para compreensão da importância de conhecer o processo de seleção dos livros disponibilizados nas bibliotecas que também envolvem múltiplos atores (agentes estatais, especialistas, escritores, docentes) e interesses.

No sexto e último capítulo, Luís Alberto Marques Alves trata do processo de avaliação dos livros didáticos em Portugal. Trata-se de uma política recente, implementada a partir de 2005, e diferente da experiência brasileira, marcada por um diálogo intenso de experiências entre avaliadores, autores e editora. Em Portugal, não há compra e distribuição gratuita de livros didáticos. Após apresentar-se o quadro de avaliação geral dos livros, é possível verificarmos que o processo de avaliação e aprovação dos livros didáticos portugueses leva em consideração o uso de fontes na construção do conhecimento histórico, o rigor científico, o multiculturalismo, a transitoriedade das interpretações históricas, a multiperspectiva, a História Local, perspectivas caras à Educação Histórica. Os avaliadores promovem sugestões aos autores e editoras, sendo possível a realização de alterações antes da publicação da obra.

Em todos os capítulos aparece a relação entre o livro didático impresso e o uso constante de novas tecnologias no ensino. Ainda não está claro se o uso das novas tecnologias irá reduzir a importância do livro didático impresso nas salas de aula; ao contrário, esses novos suportes interativos têm funcionado prioritariamente como materiais complementares aos livros, numa proposta de articulação contínua entre o livro impresso e os materiais didáticos digitais.

Apesar das diferentes realidades nacionais e especificidades nos processos de avaliação, os pesquisadores da coletânea destacam o papel do professor na 
escolha e no uso do livro didático, ressaltando a importância da formação inicial como espaço de reflexão acerca do bom uso do material didático. As avaliações são, sem dúvida, um instrumento positivo de seleção e aquisição de livros didáticos pelo Estado, a quem cabe regular e fiscalizar a qualidade da educação. No entanto, é fundamental que os professores saibam utilizar esses materiais como recurso e instrumento de aprendizagem. Os autores demonstram que as editoras estão tão atentas aos critérios estabelecidos pelos editais quanto aos critérios dos professores para a escolha do livro didático. Nesse sentido, a formação inicial adquire um lugar estratégico no treinamento e qualificação dos novos docentes quanto aos limites e possibilidades do livro didático, assim como sua responsabilidade na seleção desses materiais. A coletânea é leitura obrigatória para aqueles que pretendem compreender esse objeto complexo que é o livro didático.

\section{REFERÊNCIAS}

CAIMI, Flávia. Historiografia e livro didático: o dito e o feito na última década (19992008). In: STAMATTO, Maria. História ensinada e a escrita da história. Natal: Ed. UFRN, 2009.

MIRANDA, Sonia Regina; LUCA, Tania Regina de. O livro didático de história hoje: um panorama a partir do PNLD. Revista Brasileira de História, São Paulo: Anpuh, v.24, n.48, p.123-144, 2004.

ROCHA, Helenice. Livros didáticos de história: a diversidade de leitores e de usos. In: REZNIK, Luís; ROCHA, Helenice; MAGALHÃES, Marcelo (Org.) A História na escola. Rio de Janeiro: Ed. FGV, 2009.

Resenha recebida em 5 de maio de 2016. Aprovada em 5 de junho de 2016. 